Addressing the 'qualitative' in fuzzy set Qualitative Comparative Analysis: The generic membership Evaluation Template

\author{
Zsófia Tóth \\ Manchester Business School \\ University of Nottingham Business School \\ zsofia.toth@nottingham.ac.uk \\ Stephan C. Henneberg \\ Business Ecosystems Research Group \\ Queen Mary University of London, United Kingdom \\ s.henneberg@qmul.ac.uk \\ Peter Naudé \\ M15 6BH, UK \\ and \\ University of Sydney Business School, Sydney, NSW, Australia
}

Manchester Metropolitan University Business School, All Saints Campus, Oxford Road, Manchester, 


\begin{abstract}
Fuzzy set Qualitative Comparative Analysis (fsQCA) can help both qualitative and quantitative researchers to address causal complexity, which is the interaction between different conditions leading to the studied outcome. fsQCA is both a data analysis method and a research approach that helps investigate how alternative solutions (different configurations of conditions) make up the outcome, and considers the asymmetrical nature of social phenomena. An important challenge that researchers face when they apply fsQCA to interview data is often the lack of distinct and operationalizable anchor points for calibration. This study offers the Membership Evaluation Template (MET) to support the decision making about assigning fuzzy set values to conditions and therefore improves the transparency of the process. This paper aims to highlight why and how fsQCA can be carried out to obtain a more in-depth understanding of complex problems using interview data, to identify some core method issues involved in this analytical process, and to develop a conceptual and empirical framework that helps in managing some methodological issues, with special regard to the calibration process. For illustration of the method we scrutinize ways in which the customer can achieve attractiveness in the eyes of the supplier. Our study explores configurations leading to the Relational Attractiveness of the Customer (RAC) based on 28 in-depth interviews with senior managers on the supplier side and reflects on the analytical process of using fsQCA in this context. In the interest of methodological reflections and brevity, it is assumed that the reader is familiar with the principles of fsQCA.
\end{abstract}

\title{
Keywords
}

fuzzy set QCA, qualitative data analysis, Membership Evaluation Template, relational attractiveness, customer attractiveness 


\section{Addressing the 'qualitative' in fuzzy set Qualitative Comparative Analysis: The generic membership Evaluation Template}

\section{Introduction}

Complexity and heterogeneity are central terms in business research used in describing relational systems and dynamics within organizations. This relational complexity is multifaceted and comprises several important dimensions (Håkansson \& Ford, 2002, Holmlund, 2004; Möller \& Halinen, 1999). Some of the most studied constructs in business marketing such as trust (Morgan \& Hunt, 1994,), performance (Palmatier et al., 2007), and relationship quality (Naudé \& Buttle, 2000), are the outcomes of sets of interrelated conditions. In many respects, relational phenomena in business can be characterized as the outcome of synergies or feedback mechanisms of the constituting elements (Slater \& Narver, 1995; Forkmann et al., 2012).

Empirical research that entails efforts to address complexity normally takes either a primarily variable-focused or case-oriented view. On the one hand, the variable-focused approach is mainly quantitative and tests direct and indirect causal pathways based on the amount of variance in the dependent variable accounted by the independent variables (Hair et al., 2005). On the other hand, qualitative research drawing on data from interviews, observations, and other documents place more emphasis on selecting relevant cases and subjects and then studying them in a more comprehensive way while paying attention to contextual details and dynamics (King \& Horrock, 2010).

Despite the compelling logic of having to take sites between the breadth and depth of research, the theoretical and empirical importance of complexity and heterogeneity calls for data analytic strategies that are capable of combining the two approaches. The relevance of fsQCA particularly derives from integrating and formalizing the variable- and case-oriented 
approaches that is applicable both to qualitative as well as quantitative data (Ragin, 2009). The variable-oriented nature of fsQCA hinges on the examination of specific causal and outcome conditions and their combinations, whereas case-orientation exemplifies the minimization procedure while comparing configurations in order to select the most consistent and meaningful ones.

This combined approach of fsQCA produces configurations of conditions as typologies for complex theoretical statements that emerge as unique forms of theory building (Fiss, 2011), which by offering alternative solutions to the previously presumed "only one best way", appears to have some roots in the Popperian philosophy of falsification (Popper, 2005 [1972]). The theory-building power of fsQCA is demonstrated, for example, by Crilly's (2011) midrange theory in the context of stakeholder orientation, where a configurational approach enables the linking of conditions of resource and institutional pressures, as well as organizational attributes at the level of empirical investigation.

Even though business research and other domains would greatly benefit from applying fsQCA more extensively, researchers face methodological challenges that are not addressed or are only vaguely articulated in current literature. This study focuses on fsQCA challenges in specific contexts where quantitative anchors are normally not available for calibration (for example, in many in-depth interviews), and therefore decisions made based on qualitative understanding of dynamics and substantial knowledge of the context have an even greater influence on the outcomes of the research. This paper contributes to the real of research methodologies first by identifying the gap of systemised methodological knowledge at operational levels of the calibration process of qualitative data and second by offering the Membership Evaluation Template (MET) as a supporting tool for assigning fuzzy set values to conditions and to improve the transparency of the process. This form of calibration guidelines is not entirely new to fsQCA literature, for instance Basurto and Speer (2012) offer one. However, their study 
focuses mostly on case studies that include both primary and secondary data, and the authors largely rely on quantitative anchors derived from this variety of data, which in many cases would not be possible.

To illustrate the creation and use of MET, we use the outcome condition Relational Attractiveness of the Customer (RAC) as an example for a complex relational phenomenon (Tóth et al., 2015) for the fsQCA. RAC refers to the attitude of the managers on the supplier side towards the customer firm; in particular it comprises an evaluation of the customer company's future attractiveness as a relational partner (Manstead, 1996), and therefore RAC is essential for developing and maintaining business relationships (Harris et al., 2003). RAC is an attitudinal and perception-based construct and as such, falls into the category of not having quantitative anchor points such as actual profit or frequency of communications. Consequently, the case of RAC is appropriate in demonstrating some methodological challenges where the indicators for the calibration are not quantifiable. A total of 28 in-depth interviews were conducted with senior managers on the supplier side. These interviews provide the qualitative input data for a fuzzy set Qualitative Comparative Analysis (fsQCA) that resulted in three causal recipes for the presence of RAC and two causal recipes for the absence of RAC.

\section{Why to use fsQCA to analyze qualitative data?}

There are various benefits of using QCA for the analysis of qualitative, out of which some of the most relevant ones for qualitative research projects are as follows. First, one of the main strengths of QCA is that it combines a case-oriented and a condition-oriented view (Ragin, 1987). Qualitative researchers can greatly benefits from this, because the combination of caseand condition views enables to take a bird's eyes view on their data (Rihoux, 2013) and explore patterns systematically across the cases. These distinctive patterns are determined by the 
complexity of configurations of conditions that are present when the outcome condition is present, following the principle of equifinality (Rihoux \& Ragin, 2009), i.e. there are different potential ways to reach the same outcome.

Secondly, QCA embraces the asymmetrical and non-linear nature of social phenomena: it is capable to explore configurations of conditions not only for the outcome but the absence of the outcome as well. The configurations of the absence of the outcome are normally not simply negations of the ones of the outcome, but they show asymmetric patterns instead. This reflects on a real-life context more than a more linear approach (Woodside, 2013). The nonlinearity principle is well aligned with other qualitative methods, i.e. the changes in the conditions are not directly proportionate with changes in the outcome.

Thirdly, QCA enables the analysis of necessary conditions that explores which conditions are necessary to achieve the outcome. Necessary conditions are found in all instances of the outcome occurring (Schneider \& Wagemann, 2010). This investigation happens "in kind" and not "in degree" (compared to Necessary Condition Analysis, Dul, 2015) that is QCA shows whether a condition overall is or is not necessary, but does not provide information about the necessity of a condition at different levels of the outcome. However, this "in kind" investigation fits a qualitative approach that aims less at "in degree" explanations.

Finally, the ability of fsQCA to develop new theoretical arguments is one of the core strengths of the method. Thus, this research method responds to LaPlaca's (2014) challenge regarding the need for more explanatory approaches in order to being able to give better answers to the "How?" and "Why?" questions besides the more established "What?" question. FsQCA is especially strong in providing answers to the "How?" question by offering different causal recipes (solutions) for the same outcome (and its negation, the non-occurrence of an outcome). Therefore, applying fsQCA either as the core method of the analysis or in combination with 
other methods to the analysis of qualitative data, can strengthen the theory-building power of qualitative research.

With exploring equifinal configurations, necessary conditions and the asymmetric ways to achieve the outcome and its absence, QCA demonstrates a considerable breadth of analysis, while maintaining an in-depth understanding in describing the phenomenon. There are, however, limitations of using fsQCA. As Greckhamer et al. (2008) point out, in proving causality, fsQCA remains elusive and therefore inferences about causal relationships are based on theory or other empirical research. Another limitation is that the same conditions should appear across the examined cases in order to investigate the configurations of these conditions. Whereas less structured exploratory research with flexible or no frameworks focusing on primarily discovery, seldom meets these criteria. There are some practical limitations in the number of conditions fsQCA is capable to handle in relation to the number of studied cases (Max \& Dusa, 2011).

\section{Epistemological Background and a Configuration Approach}

The underpinning epistemological position of this study is critical realism, and hence it represents an open system view on reality (Ehret, 2013), where knowledge is fallible and theory-laden. Critical realism advocates complexity with a focus on outcomes, without the need to endure overly broad generalisations. While stating that the knowledge of reality is mediated by the researcher's perceptions, critical realism handles the social embeddedness and contextual nature of scientific inquiry: it acknowledges that social phenomena are meaningful but also that there is a real world out there, i.e. not everything is socially constructed. Sayer (2000) explains how conditions in different structures can produce events (outcomes) though causal mechanisms within a critical realist framework. This view of causation paves the way 
to a configurational approach. A critical realist view was found especially appropriate for case research (Easton, 2010). Braun and Clarke (2008) point out that in qualitative research thematic analysis is aligned with a critical realist approach because it both reflects on reality (through the lenses of the researcher) and unravels the surface of reality (structural element). Using particular frameworks represent the assumptions of reality that are inherent to this approach. However, the authors also emphasize, the vital role that transparency plays in the explanations of the researcher's choices. Because of this configurational complexity, a realist research paradigm (Bhaskar, 1975) can be regarded as more appropriate than positivism or social constructionism when aiming to investigate the Relational Attractiveness of the Customer. By using fuzzy set QCA this study subscribes to but also further methodologically enhances, this perspective on causality represented by realism, in line with recent discussions in the social sciences (Olsen, 2004). Therefore, using realism as an epistemological background looks at the causal conditions, including their interplay, as parts of a 'given' reality, and allows for a more exploratory view of the relationships between them, as well as their effect on specific outcomes.

The term 'holistic manner' has been used to describe the analytical perspective according to which parts or drivers of a phenomenon are interconnected and explicable only in the context of the whole. This is rooted in the principles of Hegelian philosophy: the whole is more than the sum of its parts and that these parts are interdependent (Phillips, 1976). The holistic view about the interdependency of conditions fits well with the configurational approach of QCA.

\section{Theoretical Framing and the Conditions}

In order to build and develop customer relationships the supplier needs to find the customer company attractive enough to do business with over time, i.e. in business markets attractiveness 
is relevant from both the customer's as well as from the supplier's perspective (Mortensen, 2012). Commitment is unlikely to be developed unless attractiveness is present (Håkansson, 1982; Halinen, 1997). However, until recently, the supplier's perspective has not been investigated in detail, and there exists a need to better understand what makes a customer company attractive in the eyes of the supplier in order to foster further relational activities in the future. Thus, the core concept is the relational attractiveness of the customer (RAC). For the purpose of this research we follow Tóth et al. (2015) in defining the phenomenon and the initial template of its drivers. RAC is an attitude of the manager at the supplier's side towards the customer firm, which incorporates previous experiences and future expectations with the supplier; therefore RAC incentivizes the supplier to maintain and/or to improve an existing business relationship with the customer by investing in the business relationship. The conditions of RAC have been identified based on Social Exchange Theory (Hald et al., 2009; Thibaut \& Kelley, 1959), because it provides a compelling explanation of how an actor decides to build or maintain relationships with other actors by weighting costs, benefits, and some other conditions. During the analysis, this template was further developed and refined as part of an 'abductive' process (Dubois \& Gadde, 2002), i.e. we started with an incomplete set of conditions that was modified.

The identified relevant conditions for achieving RAC are all based on the managerial perceptions from the supplier side. Some of them are closer to relationship performance indicators as they stem from the managerial perception, such as Financial and Non-Financial Rewards, as well as Costs, while others incorporate norms and dynamics of the relational exchange (Relational Fit with customer and the Maturity of the relationship), or the consideration of the network context (Comparison Level of Alternatives). 
Overarching cost-benefit logic, borrowed from Social Exchange Theory is a characteristic feature of the research on customer attractiveness (Ellegaard \& Ritter, 2006; Schiele et al., 2012). Applying Blau's (1964) definition of rewards into a financial context, financial rewards are the elements of the relationship that have positive value in economic terms, i.e. the current financial rewards deriving from the relationship as perceived by the manager on the supplier side, as well as anticipated/expected financial rewards, both in volume and value terms. Emerson (1976) points out that when it comes to decision-making, the solution with higher expected rewards is more likely to be chosen. While not surprising, this statement indicates the motivational power of rewards in relationship building. An overview about the rewards and other conditions of RAC is provided in Table 3.

Insert Table 2 about here

This statement, of course, applies to Non-Financial Rewards as well. Non-Financial Rewards have various forms such as emotional satisfaction and other social rewards (Lambe et al., 2001) like referrals that can influence managerial decisions (Aarikka-Stenross \& Makkonen, 2014). Also, being associated with a renowned brand (Bendixen et al., 2004) and other reputational benefits (Cook, 2005) or getting access to specific skills or knowledge (Hald et al., 2009) can be perceived as Non-Financial Rewards that increase attractiveness. For example, "I would say market knowledge, this customer also sets trends in the market, so we can see where they go, see where the industry's going from that perspective" (Managing Director; large chemical company, specialized in coatings and plastics, Company \#19) 
The Costs condition (Thibaut \& Kelley, 1959; Das \& Teng, 2002) does not refer exclusively to financial terms but to various costs of sustaining the relationship (including anticipated future costs). Therefore besides operational cost, Costs can include opportunity costs (Cook et al., 2013), time, energy invested, and emotional costs (Grassenheimer et al., 1998) of dealing with a difficult business partner. The considerations of costs are often relative, in comparison to different customers (such as time and travelling costs): "So we've got two dealers in [place A], so if I visit [place A], then I'm gone for a long time, overnight accommodation, travel costs. Whereas if I visit [another place B], I can do [place B] in a morning and be back in the office, it costs me X [less] in fuel." (Senior Dealer Marketing Manager, large automotive company, Company \#2).

In order to achieve attractiveness Trust is needed, Trust plays a vital role in exchange relationships and is created through reciprocal actions (Blau, 1964; Cropanzano \& Mitchell, 2005). Trust increases when the company meets the expectations and agreed standards, and as a consequence the role of contracts becomes less important (Macaulay, 1963). Trust shapes the exchange relationship in a way so that unpredictable predatory actions become less likely (Anderson, 1995) and conflict resolution more manageable (Anderson \& Narus, 1990). This conceptualization of the Trust condition comprises both the interpersonal and interorganizational levels as their synergy reflects on decisions and future behaviors (Zaheer et al., 1998). Molm and colleagues (2000) propose that "trust is one aspect of a broader nexus of feelings toward a partner" (p. 1398), which implies that despite the core nature of Trust, it is presumably not encompassing enough to capture the relational variety of social exchange. The same issue arises from coding of the interviews, this is why we applied an inductive approach and extended the initial Trust condition to Relational Fit. Besides Trust, the Relational Fit condition embodies a wider range of relational aspects, such as shared values and strategies 
(Mortensen et al., 2008), geographical proximity (Cantú, 2010), and similarities in ownership (for example, family and nonfamily firms, Chrisman \& Patel, 2012). Ethical considerations can also be part of the Relational Fit condition: "Our values mean we wouldn't work with a business for example that acted immorally. It might be acting legally but we wouldn't work with a business that was more like you see on TV like a loan shark company." (Managing Director, small human resource management firm, Company \#1).

Another identified condition of RAC is Dependency, which was later extended with the network aspect with the Comparison Level of Alternatives (CLA) condition. The discussion on Dependency in Social Exchange Theory dates back to Emerson's (1972) view on how power-dependency relations influence relationship development. It also addressed in the customer attractiveness literature (Mortensen, 2012; Hald, 2012). Young-Ybarra and Wiersema (1999) describe Dependency as an important social factor that evolves through heavy involvement in activities with a partner that can include various constraints. Up to a certain point Dependency is a collective incentive and safeguard to maintain the relationship, beyond that point it can impair attractiveness. The issues that arise are, for example, economic constraints, reliance on partner's skills and knowledge, as well as constraints on strategic planning. In these situations, as Lambe and colleagues (2001) point out, third party involvement becomes desirable, because the more dependent party is interested in allocating some risks and responsibilities. Whether this actually happens depends largely on the availability of alternatives (Schiele et al., 2012) and the company's level of information about them. The knowledge about potential alternatives (Thibaut \& Kelley, 1959; Schiele et al., 2012) requires some level of embeddedness in business networks (Håkansson \& Johanson, 1993). This network aspect of Dependency appeared to be a characteristic in the data as well; this is why we extended the originally planned Dependency condition to CLA. In CLA replaceability 
is an important aspect: “They're a good sized customer so if we lost the business, to replace that would be very difficult elsewhere." (Managing Director; large chemical company, specialized in coatings and plastics, Company \#19) Finally, the time perspective was introduced, encapsulated by the Relationship Maturity condition. Attractiveness changes over time as the perceived maturity of the relationship can influence the intrinsic evaluation process of the customer's attractiveness (La Rocca et al., 2012; Ellegaard \& Ritter, 2006). As emphasized by Hallé and colleagues (1991) "social exchange processes are time-dependent" (p. 35), and previous business episodes set expectations for future interactions. Jap and Ganesan (2000) suggest different categories to capture relational time: exploration, build-up, maturity, and decline. The Maturity of the relationship, however, is entirely based on the manager's perception and is not measured in the number of years or along other quantitative anchor-points. Some relationships may still be in the exploration phase after four years, while some others are already regarded as mature relationships.

\section{Sampling and Data Collection}

Depending on the type of research, QCA can involve different types of sampling procedures. Random and not random sampling techniques can result in different levels of representativeness to the studied population, and the adequacy of the sample size used also depends on the type of research and how researchers confine the definition of the target population (Short et al., 2002). The question of sampling frames within the QCA domain stems from the question of Ragin and Becker (1992) about what a case is a case of. This requires the researcher to make decisions about the universe of cases in the study and be cognizant of the potential limitations of the chosen sampling technique. 
Random sampling presumes that selected cases are general representations of the sampling universe and requires deliberately heterogeneous samples of participants, because it endeavours to collect a sample, which characteristics are aligned with the characteristics of the entire population (Colquitt, 2008). Random sampling is commonly used for traditional survey methods and has a higher ability to generalize results (Aquinis \& Edwards, 2014) compared to non-random sampling methods. Quantitative applications of QCA often use random sampling, for example Huarng et al. (2015), Longest and Thoits (2012), and Olsen et al. (2010).

However, as Greckhamer et al. (2013) point out, random sampling is not suitable for researchers predominantly interested in exploring the diversity of cases. The reason why random sampling might not be appropriate is that it may not represent the complete diversity of cases, i.e. some rather rare but theoretically relevant configurations might not often occur in larger populations and therefore require a different approach to be identified. This sampling issue applies to qualitative and quantitative as well as well as to small and large- $\mathrm{N}$ studies. Non-random sampling, especially purposive theoretical sampling select cases iteratively to develop theoretical knowledge (Glaesser \& Cooper, 2011) and enables QCA to examine commonalities across the same outcome in cases more effectively by identifying the population of cases of theoretical interest (Greckhamer et al., 2013). In this study we used purposive theoretical sampling, because we intend to examine cases that exhibit RAC to look for commonality (presence or absence of RAC) in the conditions across the cases.

Following the guidelines of Ragin (2000) about multiple sampling criteria, we identified two core steps of the sampling process: selection of companies and selection of managers within these companies. The company-related criteria were, first, that the case company should be a supplier firm to other businesses. Secondly, the case company should be an actor within a competitive market, excluding monopolistic supply relationships, because under monopolistic market conditions alternatives do not exist and the relational aspects are consequently different. 
Thirdly, the contacted suppliers have a substantial proportion of both attractive and less attractive customer companies. Manager-related sampling criteria were, first, that the responding manager has sufficient knowledge about the customer company, which typically means direct contact with the particular customer firm (in line with a key informant approach; Phillips, 1981). Secondly, purposeful sampling ensured that the manager has been involved in the decision-making process of developing, maintaining or terminating the customer relationship (Mitrega et al., 2012).

To reduce bias in potential overlaps between managerial views, the companies were contacted separately from each other (no snowball accumulation was used) based on a proprietary UK business list. The respondents were asked to select a particular business relationship to answer questions regarding RAC, without stipulating whether this relationship is more or less attractive. Data were collected from a single respondent per company that could potentially lead to common source bias in some contexts. In this research, however, the unit of analysis is the managerial perception about the attractiveness of the company and not something that can be indicated by indices, growth rates or number of partners. Table 1 shows the profiles of the supplier firms and managers interviewed as well as basic information about the chosen customer company.

Insert Table 1 about here

About one-third of the selected supplier companies are SMEs and two-thirds are larger companies (i.e. more than 250 employees). However, the size of the company was not a selection criterion, because there is no clear empirical evidence or theoretical reasoning suggesting that size of the supplier influences the perceived attractiveness of the customer. Nevertheless, dependencies in a market context can influence attractiveness (Schepis et al., 
2014; Hald et al., 2009; Emerson, 1972) and this network aspect is incorporated in the study via the Comparison Level of Alternatives (CLA) condition.

\section{Critical aspects of the within-case QCA analysis of qualitative data}

The fsQCA analysis of qualitative data starts with the systematic analysis of each case, followed by an inter-case analysis that includes the construction of the truth table and Boolean minimization of the configurations. The within-case analysis includes theoretical considerations that inform the analytical process, coding, confining membership categories for each condition, and the calibration. Considering that the process of the inter-case analysis of qualitative data is very similar to the inter-case analysis of quantitative data, this study focuses on the within-case phase of the analysis in terms of proposed methodological contributions. The problem with this analytical phase is the considerable lack of clarity, and at some point confusion, in the applied QCA literature on how to produce membership values based on qualitative data.

The significance of the problem is highlighted by previous scientific effort in regard to introduce more clarity and rigor into this process. A flagship study on this methodological challenge is Basurto and Speer (2012), in which the authors endeavour to introduce a systematic and transparent procedure to help researchers to transform qualitative data into fuzzy sets, including interviews and secondary sources. They suggest using multiple measures for each condition and that each of these measures is associated with different anchor points. For example, they scrutinize the 'Participatory Governance Condition' along measures of 'Frequency of Meetings' and 'Provision of Information' from the different actors. The 'Frequency of Meetings' measure has three anchor points: no meetings during the past year is associated with the value 0 ; around six meetings with 0.5 (neither fully in nor fully out) and 
twelve meetings or more with 1 (fully in). Despite the structured approach, the calibration of the condition, especially in case of qualitative data, is normally not a linear process. The authors encourage reviewing other important aspects, such as the interview situation, consistency of answers, and the potential availability of secondary data for triangulation. There is, however, considerable confusion around qualitative calibration process for QCA.

To shed light on the ambiguity in QCA literature on the calibration process of qualitative data, we collected and reviewed 256 articles on Google Scholar, using the keywords 'interviews', 'in-depth interviews', 'fsQCA' and 'Qualitative Comparative Analysis'. We then selected only those that conducted empirical research and used in-depth interviews as a core method by eliminating those papers from the list that only mentioned fsQCA as a potential future data analytic strategy for their research or studied fsQCA only at a theoretical basis without the use of empirical data. To our surprise, we found only a handful of qualitative fuzzy set applications (Table 2), as in the majority of the qualitative QCA projects, researchers chose crisp set QCA over fuzzy set QCA, normally without any careful considerations (for example, Coverdill \& Finlay, 1995; Rantala \& Hellström, 2001, and Marx \& Van Hootegem, 2007). Ragin (2009) explicitly warns against the inappropriate use of crisp sets because of its lower standard of settheoretic consistency. Unless the phenomena is categorical in nature (for example, member of an association or not, pregnant or not), researchers are strongly recommended to use fuzzy sets. We believe that this nearly mechanistic approach of choosing crisp sets over fsQCA in case of qualitative analysis is partly due to the ambiguity around how to carry out fuzzy set calibration on qualitative data.

Insert Table 2 about here 
Table 2 systematically reviews four critical aspects of the within-case analysis of fsQCA: the way how theory informs the analysis, the coding process, the construction of set-membership categories and the calibration. Below, we elaborate on each aspect of this framework with reflections on how this study on RAC addressed these methodological concerns.

The theoretical framework is first and most commonly used to identify causal and outcome conditions (Schneider \& Sadowski, 2010; Van der Heijden, 2014; Verweij et al., 2013). Secondly, some studies go further and pre-determine expected dimensions of the identified conditions (Basurto \& Speer, 2012) - this is a more fine-grained view and informs the coding more extensively. Thirdly, theories can provide justification why the researchers decide to take a configurational view (Basurto, 2013; Wang, 2015). Finally, theories can support hypothesis or proposition development (Basurto, 2013).

In this study the first three aspects of theory applications were carried out. Social Exchange Theory informed our understanding both in terms of the identification of conditions and their content as well as provided rationale to use fsQCA. For example, the Non-Financial Rewards condition was identified based on Social Exchange Theory and some of its dimensions derived from literature as well: brand-related (Bendixen et al., 2004) and reputational benefits (Cook, 2005) as well as rewards of effective knowledge-sharing (Hald et al., 2009). However, some dimensions, such as the value of recommendations arose from data analysis and then its potential fit with the applied theoretical framework had later been checked. The idea of 'there's no only one best way' was already apparent in Social Exchange Theory literature (especially with the different cost-benefit combinations that lead to the same outcome), yet their empirical investigation was insufficient. Using theory for validity assessment of explored dimensions of conditions is an additional (fifth) aspect that was not elaborated in the reviewed studies. 
The coding process in most reviewed studies is not very clear. Perhaps authors who do not report coding of their data skipped this analytical step (Basurto, 2013; Schneider \& Sadowski, 2010) and they used substantial case knowledge and overall impressions to perform the calibration. Coding, however, could have made the analytical process more rigorous. In studies where coding was carried out, a systematic coding scheme appeared to be highly appropriate (for example, Van der Heijden, 2014). Crilly (2011) pays attention both to the coding of the conditions and their features (for example, legitimacy pressures). Basurto and Speer (2012) drew attention to the iterative nature of their coding process.

In the current study, an initial coding scheme was applied based on Tóth et al., (2015) to identify the conditions. Template coding (King, 2004) was applied in a flexible and iterative manner, which helped to carry out the analysis in a more structured way compared to developing a priori coding. Open coding with line-by-line analysis might provide a more detailed view on the data, but researchers interested in a combination of case- and conditionoriented approaches, probably find template coding practically useful and aligned with the aims of a QCA study. Not having any initial template might result in not being able to identify the same conditions across the cases and therefore this approach can become a hurdle. The applied template consisted of the conditions Trust, Dependency, Financial and Non-Financial Rewards, and Costs as well as the outcome condition RAC. As a result of the iterative coding process applied, the initial template was extended with the time perspective (Maturity condition) and two conditions (Trust and Dependency) were extended (because previously not covered further relational aspects and the explored network perspective) into the Relational Fit and the Comparison Level of Alternatives conditions. Greckhamer et al. (2010) also mention that during the analytical process, there the replacement, addition or removal of conditions might be required. We believe that researchers should be cognizant of the advantages of using a 
template for the coding (and the risks of not having one) but at the same time be prepared to make amendments in it.

The decision about set-membership categories usually varies between 4-value (Basurto \& Speer, 2012; Van der Heijden,, 2014, Verweij et al., 2013) and 6-value sets (Basurto, 2013), or sometimes a combination of these two (Crilly, 2011; Schneider \& Sadowski, 2010). Usually there are no plausible explanations or descriptions offered of the fuzzy set inquiry. When it comes to constructing fuzzy sets, the researcher needs to be cognizant of that first, they display both qualitative (in kind) and quantitative (in degree) characteristics and are not rankings or ordinal scales (Ragin, 2009). For example, in case of RAC, 1 does not represent the most attractive and 0 the least attractive customer relationship, but these values represent to what extent the studied relationships are members in the set of attractive customer relationships. Secondly, the point of orientation should always be theoretical and substantial case knowledge about the universe of cases and not the sample in a restrictive way. For instance, if we had RAC cases that all show reasonably or very strong Relational Fit (one of the conditions of $\mathrm{RAC}$ ), this does not mean that 'the full non-membership (0) of customer relationships with good relational fit' should apply already for reasonably strong fits, just because these represent the "weakest" cases in the sample. Thirdly, odd-number fuzzy sets imply that there is a set "in the middle' with maximum ambiguity, which is 'neither in nor out'. Therefore, unless there's a strong theoretical argument against it, using fuzzy sets with even number value categories can avoid some membership-related ambiguity in the fsQCA procedure. Finally, the decision about which fuzzy sets should be used, i.e. four-, six-, or more value fuzzy sets, should be based on qualitative understanding and/or theoretical knowledge and consideration of which provides a better representation of empirical evidence. In the reviewed qualitative fsQCA applications, 4- and 6-value sets deem to be appropriate, especially where no additional sources (e.g. 
different types and sources of data) are available to create a more fine-grained specification. If using 6-value set implies making artificial distinctions, the researcher should stay with a 4value set. If the 4-value set appears to be constraining, the 6-value set should be chosen. Using both 4- and 6-value fuzzy sets for different conditions within the same analysis is suitable (Ragin, personal correspondence, 25 August 2015).

In this study 6-value fuzzy sets were applied to most conditions, because these provided a relatively fine-grained specification without creating artificial differences. 4-value fuzzy sets were applied to the Maturity condition and RAC. Theory informed the 4-value decision of the 'membership in mature customer relationships' set, because Jap and Ganesan (2000) proposed a four-group categorisation of relationship maturity that has previously applied in the context of attractiveness (Baxter, 2012; Mortensen \& Arlbjørn, 2012; Nollet et al., 2012).

These maturity categories were not applied in this study in a linear way but they informed the set-selection by making qualitative breakpoints for a 4-value fuzzy set more clear, compared to alternative fuzzy sets with higher number of categories. In most RAC cases both 4- and 6value fuzzy sets tended to be appropriate but there were cases where applying a 6-value fuzzy set would have required some artificial distinctions, especially between the "mostly but not fully in' $(0.8)$ and 'more or less in' (0.6) values and we wanted to avoid the risk of consequent inaccuracy. Assuming that attractiveness belongs to the eyes of the beholder (Ellegaard \& Ritter, 2006), it worth considering the level of elaboration of RAC in managerial narratives.

The calibration procedure is described vaguely if at all in most of the reviewed studied. A characteristic approach is to refer to quantitative anchors (for example, frequency of meetings) and briefly mention that qualitative aspects were carefully considered but leave the reader with little or no explanation (Schneider \& Sadowski, 2010; Verweij et al., 2013; Wang, 2015). With introducing a systematic logic into the within-case analysis, Basurto and Speer (2012) had 
made appreciable strides, however, the fact that qualitative in-depth interviews seldom have sufficient quantitative anchors, remains largely disregarded. In fact, we argue that overly emphasizing the role of quantitative anchors in the calibration of qualitative data can be misleading, yet the simplification has some advantages in terms of transparency and structure. For example, in the example of Basurto and Speer (2012), could effective 'Participatory Governance' be 'measured' based on the number of meetings, participants and amount of impact delivered by the participants? Even though the authors vaguely mention that they take some qualitative aspects into consideration, this remains unrevealed in the explained calibration process. Through providing some suggestions on how to create qualitative anchors for the fuzzy set calibration with the help of the Membership Evaluation Template, we strive for a good balance between qualitative and quantitative anchors, where this is applicable. Also, in cases where no or just minimal quantifiable information is available, the Membership Evaluation template can help researchers collecting and structuring relevant information for the calibration.

\section{Working with qualitative anchors: Introducing the Membership Evaluation Template}

The systematic review on empirical QCA studies using qualitative data highlights the confusion about how to do the calibration for the configurational analysis. Two core calibration strategies were explored. First strategy is the 'crispification', i.e. the dichotomisation of data despite the complex nature of most social phenomena that seldom occur in dichotomies (Schneider \& Wagemann, 2012). This act often forces an artificial simplification on the analytical process that might result in higher consistency scores (as shown by Ragin, 2009) but 
at the same time has significant costs by losing interesting and relevant shades of the data, which could have been better addressed better with fsQCA than with csQCA.

The second strategy is the introduction of 'quantitative anchors' that seems to be somewhat better than 'crispification', because quantitative anchors do not restrict the variation of social phenomena to the extent dichotomization does. However, they do shift qualitative data analysis towards focusing on synthetic measures that are not necessary central to the in-depth understanding of the phenomenon. For example, focusing on the frequency of meetings and the amount of information delivered in order to operationalize the 'Participatory governance' condition (Basurto \& Speer, 2012), might hinder a more in-depth understanding of the phenomenon such as the active nature of citizenship behavior, attitudes towards the state, transformative approach of citizens, tendency towards hiding or publicizing power conflicts, internalization of dominant ideologies (Hickey \& Mohan, 2004) or any other relevant dimensions, which might arose during the interviews.

We propose a third way of fsQCA calibration that does not force dichotomy on complex social phenomena and embraces the qualitative nature of the research. We offer a template (Membership Evaluation Template, Table 4) to study the dimensions of the condition in question and their specificities. The example of the calibration is demonstrated on the Relational Fit condition. Each template indicates a case number (alternatively names of interviewees / companies) and the specification of what sort of membership are we looking at (here: the membership in customer relationships with good relational fit). This is followed by a brief overall case-description with special regard to the studied condition. This is a reminder for the researcher about the relational context and some potential core issues.

Insert Table 4 about here 
The first column 'Dimensions' (\#1) lists the explored dimensions of the 'Relational Fit' condition for this specific case, followed by a brief context-specific description (\#2) in the second column. Some of the explored dimensions in this case are as follows: the customer firm's opportunistic behavior, appreciation of professional trust, and differences in organizational cultures. These dimensions, however, might have a different 'weight' in the argumentation; some of them play a more important role than others depending on the managers' interpretation. The researcher should ask her/himself questions about the interviewees' behavior such as: Did they put emphasis on a specific dimension? Did they repeat it in different forms during the interview? Did they become nervous, angry or emotional when talking about that dimension? Did maybe the pace, strength of voice or tone changed due to the topic? This contextual embeddedness is expressed in Column \#3 (Intensity / Relative Importance). Besides the intensity, the dimension's effect (direction) on the outcome condition is also relevant (\#4). In this context effect is not understood as direct cause-effect relationship but the dimension's relative relation to the outcome. Certainly, the appreciation of the partner's professionalism (while highlighting the importance of professionalism at his/her company) is something that is positively associated with a good relational fit, while blaming the customer for their opportunistic behavior is not that much so. The dimensions can be supported by some illustrative quotes (\#5), which are characteristic elements of their overall understanding.

The Membership Evaluation Template is tailored primarily for the analysis of in-depth interviews where quantitative anchors are not available. It can be easily combined with thematic coding and the template analysis for the codes, especially if the sample is small or medium-sized. Ideally the template is used for each case (for this research: each interview) and each condition is evaluated following the same procedure. This procedure aims at offering 
some 'qualitative anchors' for the calibration where 'quantitative anchors' are less relevant or not available.

In a final evaluation of the membership of the case in the set of customer relationships with good relational fit, in a 6-value set, 'full membership' (1) would be indicated by various and/or some intense positive (supporting) dimensions with no or negligible negative dimensions. 'Mostly but not fully in' (0.8) membership is indicated by intense (and/or various) positive dimensions with very few negative dimensions. The overall positive, supporting role of these dimensions towards the outcome is less explicit than in case of full membership. The 'more or less in' (0.6) membership can be described by mostly positive dimensions with some considerable negative dimensions. In case of the 'more or less out' $(0.4)$ membership negative dimensions override the positive ones (in variety/intensity) but still some important positive dimensions are present. The 'mostly but not fully out' $(0.2)$ is represented by various/intense negative dimensions with very few positive dimensions that in volume and value cannot balance the negative ones. The 'fully out' (0) is an obvious case of the dominance of intense/various negative dimensions from the perspective of the studied condition.

The final evaluation, however, can include supporting quantitative information (for example, frequency of meetings if this is applicable in the context), as it is indicated in the row before the last row of the template. However, unless it has theoretical or empirical relevance, these quantitative measures do not play a leading role in the calibration process of primarily qualitative data.

The rigour of this way of qualitative calibration does not rely on following additional computational rules but on the care with which the template helps to explore and systemize qualitative data. The final evaluation of qualitative anchors is not automatic and requires the researcher qualitative assessment, but the template enables a well-informed decision making 
that is aligned with an in-depth qualitative approach. The Membership Evaluation Template proved to be especially useful during the discussion about coding and calibration between two coders, following the guidelines of Henik (2014).

\section{Inter-case Analysis and Findings}

\subsection{Truth Table and Boolean Analytical Basis}

The information from the calibrated dataset (i.e. fuzzy values were identified based on qualitative data by case for the conditions and the outcome) is summarized in the truth table by sorting cases into $2^{\mathrm{k}}$ logically possible combinations (truth table rows), where $k$ is the number of conditions - in this study this means $64\left(2^{6}\right)$ theoretical combinations. After constructing the truth table, Fiss (2011) describes logical minimization, and the production of simplified combinations based on Boolean algebra. The general purpose of the minimization process is to simplify the information in the truth table by dropping logically redundant conditions (Rohlfing, 2012) and producing the formula for sufficiency (Schneider \& Wagemann, 2012). The minimization process includes two main stages: first, limiting the analysis only to those rows in the truth table that have a minimum number of cases (in this study at least one case). Logical remainders are configurations (i.e. lines in the truth table) which are logically correct but have no observations and depend on the researcher's decision whether to include any of these cases based on theoretical reasoning (Fritzsche, 2013). In this study, only empirically observed configurations were included and others were treated as remainders. Secondly, minimum consistency levels for solutions are considered. The consistency cut-off for the configurations in the truth table was set at 0.9 (there is an ongoing discussion about the lowest acceptable threshold, which is often set at 0.75 , but generally speaking the higher consistency the better; Schneider \& Wagemann, 2010). The truth table rows were reduced to simplified 
combinations based on Boolean algebra (Rihoux \& Ragin, 2009) that resulted in the solution formula with multiple paths (equifinality).

\subsection{Analysis and Results}

A condition is necessary if whenever the outcome is present, the condition is also present. But there can be cases that are members of the condition but not the outcome (Schneider \& Wagemann, 2010), therefore the analysis of necessary conditions assesses the consistency with which instances of the outcome displaying the causal condition tend to be necessary (Ragin, 2008). A minimum level of a 0.9 consistency is suggested for the analysis of necessary conditions (Fiss, 2007; Ragin, 2008). None of the conditions in this study exceeded the consistency level of 0.9 , therefore there are no necessary conditions in the solutions based on this threshold (in line with proposition 4). A condition is sufficient whenever the condition is present and the outcome is present too, or more generally speaking the condition can be regarded as sufficient if, across the cases, set membership in it is lower than or equal to each case's membership in the outcome (Schneider \& Wagemann, 2012). The raw coverage is the percentage of all cases' set membership in the outcome and is covered by a single path. Unique coverage shows the percentage of all cases' set membership in the outcome uniquely covered by a single path (Ragin, 2008). Table 5 shows the results of the fsQCA, four solutions for the presence of RAC (High RAC) and two solutions for the absence of RAC (Not-High RAC). For the interpretation of the solution tables the format published by Ragin and Fiss (2008) is applied. The black circles indicate the presence of a condition; circles with ' $X$ ' indicate the absence, while large circles indicate core conditions, whereas small ones are peripheral conditions.

\subsubsection{Configurations for $R A C$ and for the Absence of $R A C$}


There are four sufficient configurations for RAC that all pass the minimum threshold of consistency. This applies to the overall solution consistency as well. In terms of coverage, the solutions account for 70 percent of membership in the group achieving RAC, which represents a high coverage value (comparable to the $\mathrm{R}^{2}$ variance explained indicator of variable-based analysis; Schneider \& Grofman, 2006). There are two solutions offered for not mature relationships (1b and 1c), one for mature relationships (1d) and for one solution maturity does not matter. Also, there are different solutions provided for high CLA (1b and 1d), low CLA (1a; more specifically in cases with low membership in customer relationships with high CLA), and also there is a solution (1b) where it does not matter whether CLA is high or low.

Insert Table 5 about here

For the Absence of RAC two solutions were identified. In the case of 2 a maturity does not matter but the CLA is low, whereas in 2b CLA does not matter but the relationship is less mature. The solution consistency for the Absence of RAC calculations is high with a value of 0.94, with a reasonable coverage of 52 percent. Although no necessary conditions are identified, the lack of Costs (that is low membership levels in the customer relationship with high Costs) for RAC, the lack of Relational Fit (low membership level in the customer relationship with good Relational Fit) and the lack of Financial Rewards (low membership level in the customer relationship with high Financial Rewards) for the Absence of RAC are relatively close to the necessity threshold. It is arguable that these therefore represent necessary conditions in a practical sense (Olsen, 2009). The analysis of core and peripheral conditions shows that lack of maturity, the presence of non-financial rewards and relational fit are core conditions for RAC (and in solution $1 \mathrm{~b}$ the absence of financial rewards is a core condition besides the presence of non-financial benefits), and that all others are peripheral conditions. 
For the Absence of RAC, the absence of non-financial rewards and the presence of costs proved to be core conditions.

The Boolean formula represents the briefest way of describing a functionally complete logic system (Kabanets \& Cai, 2000). The Boolean formula for the four configurations leading to $\mathrm{RAC}$ is:

$$
\begin{aligned}
\sim C O S *[R E L F * & F R *(N F R * \sim C L A+\sim M A T * \sim N F R)+C L A *(M A T * R E L F+\sim M A T * \sim F R * N F R)] \\
& \rightarrow R A C
\end{aligned}
$$

The simplified formula shows that besides the absence of Costs there are more alternative ways to achieve attractiveness: either a combination of Relational Fit, Financial Rewards and some other conditions or CLA and Relational Fit (if it is a more Mature relationship) or CLA and Non-Financial Rewards (even though when Financial Rewards is absent, but the relationship is not a Mature relationship). The second Boolean formula shows that a common trait to achieve the Absence of RAC is when managing the relationship is expensive, it does not result in major Financial or Non-Financial Rewards and the Relational Fit is not very good:

$\operatorname{COS} * \sim F R * \sim N F R * \sim R E L F *(\sim C L A+\sim M A T) \rightarrow \sim R A C$

Where " $\sim$ " is the absence of a condition, "*" is the "logical and" and "+" is the "logical or" and the abbreviations are as follows: MAT maturity, FR financial rewards, NFR non-financial rewards, COS costs and CLA comparison level of alternatives.

\subsubsection{Configurations for Very High RAC}

The analysis of extreme outcomes is demonstrated by Fiss (2011). Such an analysis explores how Very High RAC can be achieved, thereby extending the search for RAC. This requires recalibration that is about assigning new values to the RAC condition with a different reference point that is Very High RAC that is different to RAC. For example, a case where the customer firm was somewhat attractive (membership of RAC "more in than out", but close to "neither in nor out") has set membership of "more out than in" when the question is the membership in Very High RAC. The previous calibration of other conditions, however, remains unchanged. 
Table 6 shows the results of the fuzzy set QCA analysis of Very High RAC, with only one sufficient configuration existing, showing a reasonably high raw coverage (47 percent).

Insert Table 6 about here

Not surprisingly, Very High RAC can be achieved through the combination of Financial as well as Non-Financial Benefits, the lack of Costs, low CLA, and good Relational Fit. However, these conditions were combined with low Relationship Maturity, i.e. at early stages of the relationship customers could achieve extreme levels of attractiveness while such an extreme outcome could not be replicated in more mature relationships. Furthermore, a sensitivity analysis was carried out by checking configurations at different consistency levels $(0.75,0.80$, 0.90) but only minor changes were observed regarding neutral permutations that occur and the specific number of solutions, while the interpretation of the results remained substantively the same (Fiss, 2011). Therefore, the results of the fuzzy set QCA are robust.

\section{Discussion and Conclusions}

This study applies fsQCA to the analysis of qualitative data and introduces the Membership Evaluation Template to bring more clarity into the qualitative calibration process that often lacks quantitative anchor-points. Through the systematic review of previous fsQCA studies based on qualitative data, we identify some practices, issues and suggestion about how theory can inform the analytical process, ways of coding, construction of set-membership categories and the calibration process.

Theory can inform fsQCA in various ways: with identification of conditions, the dimensions of these conditions and the relationship between them. If a configurational approach is present 
at a theoretical level, this could provide a good rationale for applying fsQCA empirically to investigate the phenomenon. Also, theories can support hypothesis and propositiondevelopment, although exploratory qualitative research might not require statement to test at all.

For the coding process we recommend using a template based on previous literature and make changes in the template along the way if needed. Some of the conditions might need further development or new conditions might be needed or need to be eliminated. Without an initial template, however, there is a considerable risk of not being able to find the same conditions in each case that can make fsQCA more difficult if not impossible.

For the identification of set membership categories even numbers are normally more favorable, because the ambiguity around 'neither in, nor out' of membership can be avoided this way. Four- and six-value fuzzy sets tend to be highly appropriate where only interview data was available without quantitative anchors. Different types of fuzzy sets can be combined within the same study, but crisp sets are not recommended unless the phenomenon is dichotomous in nature.

The calibration is the most 'fuzzy' part of qualitative QCA studies. Many authors choose crisps sets instead or apply quantitative anchors where applicable. We introduce the Membership Evaluation Template that helps to identify some qualitative anchors by considering different dimensions of a condition, the intensity and negative/positive nature of these dimensions in respect to the outcome and their context. The template can include quantitative anchors as well but aims primarily on the calibration of qualitative data. Besides these methodological benefits, the template can increase the transparency of the calibration process.

The study has some theoretical advancement as well. Based on 28 in-depth interviews with senior managers on the supplier side from various industries in the UK, we applied fuzzy set 
Qualitative Comparative Analysis to explore how the customer firm can achieve attractiveness in the eyes of the supplier. This study develops a deeper contextual understanding on the configurations of RAC by incorporating a broader relational perspective (Relational Fit), the network angle (Comparison Level of Alternatives) and adds the time perspective by introducing Maturity as a new condition besides the previously addressed costs-rewards considerations (Costs, Financial and Non-Financial Rewards). The results show four equifinal configurations of these conditions that lead to RAC, and two that lead to the absence of RAC.

The Trust condition of RAC in previous research (Tóth et al., 2015) was extended to the condition Relational Fit, which incorporates more relational aspects than Trust and therefore increases the explanatory power of the explored configurations. Also, the previous Dependency condition was enhanced by the network perspective and is represented in this study as the Comparison Level of Alternatives condition. Our first and third configurations are consistent with the findings of previous research. Some new insights regarding the composition of the configurations emerge: the second configuration of RAC shows that in non-mature relationships with the availability of potential alternatives, the customer can achieve attractiveness in the eyes of the supplier if they associate major Non-Financial Rewards with the relationship. The fourth configuration shows that in a mature relationship, even when alternatives are available, good Relational Fit together with the absence of Costs can make the customer attractive, no matter whether Rewards are present. Two explored configurations demonstrate that attractiveness can be achieved even without major Financial Benefits, particularly if it is either a less mature relationship (along with the presence of Non-Financial Benefits) or a mature relationship (along with the absence of Costs and a good Relational Fit). 


\section{References}

Aarikka-Stenroos, L., \& Makkonen, H. S. (2014). Industrial buyers' use of references, wordof-mouth and reputation in complex buying situation. Journal of Business \& Industrial Marketing, 29(4), 344-352.

Anderson, J. C. (1995). Relationships in business markets: Exchange episodes, value creation, and their empirical assessment. Journal of the Academy of Marketing Sciences, 23(4), 346350 .

Anderson, J. C., \& Narus, J. A. (1990). A model of distributor firm and manufacturer firm working partnerships. Journal of Marketing, 54(1), 42-58.

Aguinis, H., \& Edwards, J. R. (2014). Methodological wishes for the next decade and how to make wishes come true. Journal of Management Studies, 51(1), 143-174.

Basurto, X. (2013). Linking multi-level governance to local common-pool resource theory using fuzzy-set qualitative comparative analysis: insights from twenty years of biodiversity conservation in Costa Rica. Global Environmental Change, 23(3), 573-587.

Basurto, X., \& Speer, J. (2012). Structuring the calibration of qualitative data as sets for Qualitative Comparative Analysis (QCA), Field Methods, 24(2), 155-174.

Bazeley, P. (2007). Qualitative analysis with NVivo, London: Sage.

Baxter, R. (2012). How can business buyers attract sellers' resources? Empirical evidence for preferred customer treatment from suppliers. Industrial Marketing Management, 41(8), $1249-1258$

Bendixen, M., Bukasa, K. A., \& Abratt, R. (2004). Brand equity in the business-to-business market. Industrial Marketing Management, 33(5), 371-380.

Bhaskar, R. (1975). Forms of realism, Philosophica, 15(1), 99-127.

Blau, P. M. (1964). Power and exchange in social life, New York: Wiley \& Sons.

Braun, V., \& Clarke, V. (2008). Using thematic analysis in psychology, Qualitative Research in Psychology, 3(2), 77-101.

Byrne, D., \& Ragin, C. C. (Eds.) (2009). The Sage handbook of case-based methods. London: Sage.

Cantù, C. (2010). Exploring the role of spatial relationships to transform knowledge in a business idea-Beyond a geographic proximity. Industrial Marketing Management, 39(6), 887-897.

Chrisman, J. J., \& Patel, P. C. (2012). Variations in R\&D investments of family and nonfamily firms: Behavioral agency and myopic loss aversion perspectives. Academy of management Journal, 55(4), 976-997.

Colquitt, J. A. (2008). From the editors publishing laboratory research in AMJ: A question of when, not if. Academy of Management Journal, 51(4), 616-620.

Cook, K. S. (2005). Networks, norms, and trust: The social psychology of social capital. Social Psychology Quarterly, 68(1), 4-14.

Cook, K. S., Cheshire, C., Rice, E. R., \& Nakagawa, S. (2013). Social exchange theory. In: Handbook of Social Psychology, Springer Netherlands, 61-88.

Cook, K. S., \& Rice, E. (2003). Social exchange theory. In DeLamater, I. (Ed.). Handbook of social psychology. New York: Kluwer Academic Plenum, 53-76. 
Cordón, C., \& Vollmann, T. E. (2002). The next game in purchasing: Be the most attractive customer to key suppliers. IMD International, 86, January.

Coverdill, J. E., \& Finlay, W. (1995). Understanding Mills via Mill-type methods: An application of qualitative comparative analysis to a study of labor management in southern textile manufacturing. Qualitative Sociology, 18(4), 457-478.

Crilly, D. (2011). Predicting stakeholder orientation in the multinational enterprise: A midrange theory. Journal of International Business Studies, 42(5), 694-717.

Cropanzano, R., \& Mitchell, M. S. (2005). Social exchange theory: An interdisciplinary review. Journal of Management, 31(6), 874-900.

Das, T. K., \& Teng, B. S. (2002). Alliance constellations: A social exchange perspective. Academy of Management Review, 27(3), 445-456.

Dubois, A., \& Gadde, L. E. (2002). Systematic combining: an abductive approach to case research. Journal of Business Research, 55(7), 553-560.

Dul, J. (2015). Necessary Condition Analysis (NCA): Logic and Methodology of "Necessary but Not Sufficient" Causality. Organizational Research Methods, 7, 1-43.

Easton, G. (2010). Critical realism in case study research. Industrial Marketing Management, $39(1), 118-128$.

Ehret, M. (2013). Emergence of business markets - A critical realist foundation. Industrial Marketing Management, 42(3), 316-323.

Ellegaard, C., \& Ritter, T. (2006). Customer attraction and its purchasing potential, Conferemce Paper, 22nd IMP Conference, Milan, Italy.

Emerson, R. M. (1962). Power-dependence relations. American Sociological Review, 27(1), $31-41$.

Emerson, R. M. (1972). Exchange theory: Exchange relations and networks. Sociological Theories in Progress, 2, 58-87.

Emerson, R. M. (1976). Social exchange theory. Annual Review of Sociology, 2, 335-362.

Fiss, P. (2007). A set-theoretic approach to organizational configurations. Academy of Management Review, 32(4), 1180-1198.

Fiss, P. C. (2011). Building better causal theories: A fuzzy set approach to typologies in organization research. Academy of Management Journal, 54(2), 393-420.

Forkmann, S., Wang, D., Henneberg, S. C., Naudé, P., \& Sutcliffe, A. (2012). Strategic decision making in business relationships: A dyadic agent-based simulation approach. Industrial Marketing Management, 41(5), 816-830.

Fritzsche, E. (2013). Making hermeneutics explicit: how QCA supports an insightful dialogue between theory and cases. International Journal of Social Research Methodology, 17(4), 403-426.

Gassenheimer, J. B., Houston, F. S., \& Davis, J. C. (1998). The role of economic value, social value, and perceptions of fairness in interorganizational relationship retention decisions. Journal of the Academy of Marketing Science, 26(4), 322-337.

Glaesser, J., \& Cooper, B. (2011). Selecting cases for in-depth study from a survey dataset: an application of Ragin's configurational methods. Methodological Innovations Online, 6(2), $52-70$. 
Greckhamer, T., Misangyi, V. F., Elms, H., \& Lacey, R. (2008). Using QCA in strategic management research: An examination of combinations of industry, corporate, and business unit effects. Organizational Research Methods, 11(4), 695-726.

Greckhamer, T., Misangyi, V. F., \& Fiss, P. C. (2013). The Two QCAs: From a Small-N to a Large-N Set Theoretic Approach. In Fiss, P. C., Cambré, B., \& Marx, A. (Eds.). Configurational Theory and Methods in Organizational Research, Research in the Sociology of Organizations, 38, 49-75.

Håkansson, H. (Ed.) (1982). International marketing and purchasing of industrial goods: An interaction approach, Chichester: John Wiley \& Sons.

Håkansson, H., \& Ford, D. (2002). How should companies interact in business networks? Journal of Business Research, 55(2), 133-139.

Håkansson, H., \& Johanson, J. (1993). The network as a governance structure: Interfirm cooperation beyond markets and hierarchies. In Grabher, G. (Ed.). The Embedded Firm, London: Routledge.

Hair, J. F., Black, B., Babin, B., Anderson, R. E., \& Tatham, R. L. (2005). Multivariate Data Analysis. Upper Saddle River NJ: Prentice Hall.

Hald, K. S., Cordón, C., \& Vollmann, T. E. (2009). Towards an understanding of attraction in buyer-supplier relationships. Industrial Marketing Management, 38(8), 960-970.

Hald, K. S. (2012). The role of boundary spanners in the formation of customer attractiveness. Industrial Marketing Management, 41(8), 1228-1240.

Halinen, A. (1997). Relationship Marketing in Professional Services: A Study of Agency Client Dynamics in the Advertising Sector, London: Routledge.

Hallén, L., Johanson, J., \& Seyed-Mohamed, N. (1991). Interfirm adaptation in business relationships. Journal of Marketing, 55(2), 29-37.

Harris, L. C., O'Malley, L., \& Patterson, M. (2003). Professional interaction: Exploring the concept of attraction. Marketing Theory, 3(1), 9-36.

Hartley, J. (1994). Case studies in organizational research. In Cassell, C. \& Symon, G. (Eds.). Qualitative methods in organizational research, a practical guide, London: Sage, 208-229.

Harwood, T. G., \& Garry, T. (2003). An overview of content analysis. The Marketing Review, $3(4), 479-498$.

Henik, E. (2014). Understanding whistle-blowing: a set-theoretic approach. Journal of Business Research, forthcoming, doi:10.1016/j.jbusres.2014.06.004

Hickey, S. \& Mohan, G. (2004). Participation: from tyranny to transformation? Exploring new approaches to participation in development. Zed Books: London.

Holmlund, M. (2004). Analyzing business relationships and distinguishing different interaction levels. Industrial Marketing Management, 33(4), 279-287.

Huarng, K. H., Yu, T. H. K., \& Lai, W. (2015). Innovation and diffusion of high-tech products, services, and systems. Journal of Business Research, 68(11), 2223-2226.

Jap, S. D., \& Ganesan, S. (2000). Control mechanisms and the relationship life cycle: implications for safeguarding specific investments and developing commitment. Journal of Marketing Research, 37(2), 227-245.

Kabanets, V., \& Cai, J.-Y. (2000). Circuit minimization problem, Proceedings at the $32^{\text {nd }}$ Symposium on Theory of Computing, Portland, Oregon, United States, 73-79. 
King, N. (2004). Using templates in the thematic analysis of text. In Cassell, C., \& Symon, G. (Eds.). Essential guide to qualitative methods in organizational research. Sage: London, 256-270.

King, N., \& Horrocks, C. (2010). Interviews in Qualitative Research. Sage: London.

La Rocca, A., Caruana, A., \& Snehota, I. (2012). Measuring customer attractiveness. Industrial Marketing Management, 41(8), 1241-1248.

Lambe, C. J., Wittmann, C. M., \& Spekman, R. E. (2001). Social exchange theory and research on business-to-business relational exchange. Journal of Business-to-Business Marketing, $8(3), 1-36$.

LaPlaca, P. (2014). Advancing industrial marketing theory: The need for improved research, Journal of Business Market Management, 7(1), 284-288.

La Rocca, A., Caruana, A., \& Snehota, I. (2012). Measuring customer attractiveness. Industrial Marketing Management, 41(8), 1241-1248.

Leischnig, A., \& Kasper-Brauer, K. (2014). Employee adaptive behavior in service enactments. Journal of Business Research, forthcoming, doi:10.1016/j.jbusres.2014.07.008

Longest, K. C., \& Thoits, P. A. (2012). Gender, the Stress Process, and Health A Configurational Approach. Society and Mental Health, 2(3), 187-206.

Macaulay, S. (1963). Non-contractual relations in business: A preliminary study. American Sociological Review, 28, 55-69.

Mackenzie, H. F. \& Hardy, K. G. (1996). Manage your offering or manage your relationship? Journal of Business \& Industrial Marketing, 11(6), 20-37.

Manstead, A. S. (1996). Attitudes and behaviour. In Semin, G. R., \& Fiedler, K. (Eds.). Applied Social Psychology, London: Sage, 3-29.

Marx, A., \& Dusa, A. (2011). Crisp-Set Qualitative Comparative Analysis (csQCA): Contradictions and consistency benchmarks for model specification. Methodological Innovations Online, 6(2), 103-148.

Marx, A., \& Van Hootegem, G. (2007). Comparative configurational case analysis of ergonomic injuries. Journal of Business Research, 60(5), 522-530.

Merton, R. C. (1975). An asymptotic theory of growth under uncertainty. The Review of Economic Studies, 42, 375-393.

Mitrega, M., Forkmann, S., Ramos, C., \& Henneberg, S. C. (2012). Networking capability in business relationships - Concept and scale development. Industrial Marketing Management, 41(5), 739-751.

Möller, K. K., \& Halinen, A. (1999). Business relationships and networks: Managerial challenge of network era. Industrial Marketing Management, 28(5), 413-427.

Molm, L. D. (1991). Affect and social exchange: Satisfaction in power-dependence relations. American Sociological Review, 56, 475-493.

Molm, L. D., Takahashi, N., \& Peterson, G. (2000). Risk and trust in social exchange: An experimental test of a classical proposition. American Journal of Sociology, 105(5), 13961427.

Morgan, R. M., \& Hunt, S. D. (1994). The commitment-trust theory of relationship marketing. Journal of Marketing, 58(3), 20-38. 
Mortensen, M. H. (2012). Understanding attractiveness in business relationships - A complete literature review. Industrial Marketing Management, 41(8), 1206-1218.

Mortensen, M., \& Arlbjørn, J. (2012). Inter-organisational supplier development: the case of customer attractiveness and strategic fit. Supply Chain Management: An International Journal, 17(2), 152-171.

Mortensen, M. H., Freytag, P. V., \& Arlbjørn, J. S. (2008). Attractiveness in supply chains: a process and matureness perspective. International Journal of Physical Distribution \& Logistics Management, 38(10), 799-815.

Naudé, P., \& Buttle, F. (2000). Assessing relationship quality. Industrial Marketing Management, 29(4), 351-361.

Nollet, J., Rebolledo, C., \& Popel, V. (2012). Becoming a preferred customer one step at a time. Industrial Marketing Management, 41(8), 1186-1193.

Olsen, W. (2004). Triangulation in social research: qualitative and quantitative methods can really be mixed. Developments in Sociology, 20, 103-118.

Olsen, W. (2009). Non-nested and nested cases in a socio-economic village study. Handbook of Case-Centred Methods, London: Sage.

Olsen, W., Harriss-White, B., Vera-Sanso, P., \& Suresh, V. (2010). The experience of slum dwellers in Chennai under the economic and environmental insults of 2008-9. In Paper for the Conference on 'The Hidden Contribution of Older People: Rethinking Age Poverty Opportunity and Livelihoods, Centre for Law, Policy and Human Rights Studies and the Department of Humanities and Social Sciences', March 2010, Chennai, India

Palmatier, R. W., Dant, R. P., \& Grewal, D. (2007). A comparative longitudinal analysis of theoretical perspectives of interorganizational relationship performance. Journal of Marketing, 71(4), 172-194.

Phillips, L. W. (1981). Assessing measurement error in key informant reports: A methodological note on organizational analysis in marketing. Journal of Marketing Research, 18(4), 395-415.

Popper, K. (2005[1972]). The logic of scientific discovery. Routledge: New York.

Ragin, C. C. (1987). The comparative method. Moving beyond qualitative and quantitative methods, Berkeley: University of California.

Ragin, C. C. (2000). Fuzzy-set social science, Chicago: University of Chicago Press.

Ragin, C. C. (2008). Redesigning social inquiry: Fuzzy sets and beyond, Chicago: University of Chicago Press, 190-212.

Ragin, C. C., \& Becker, H. S. (1992) (Eds.). What is a case? Exploring the foundations of social inquiry. Cambridge: Cambridge University Press.Ragin, C. C., \& Fiss, P. C. (2008). Net effects analysis versus configurational analysis: An empirical demonstration. In C.C. Ragin (Ed.). Redesigning social inquiry: Fuzzy sets and beyond. Chicago: University of Chicago Press, 190-212.

Ramos, C., Henneberg, S. C., \& Naudé, P. (2012). Understanding network picture complexity: An empirical analysis of contextual factors. Industrial Marketing Management, 41(6), 951972.

Rantala, K., \& Hellström, E. (2001). Qualitative comparative analysis and a hermeneutic approach to interview data. International Journal of Social Research Methodology. 4(2), 87-100. 
Rihoux, B., \& Ragin, C. C. (2008). Configurational comparative analysis. London: Sage.

Rihoux, B., \& Ragin, C. C. (Eds.) (2009). Configurational comparative methods: Qualitative comparative analysis (QCA) and related techniques. London: Sage.

Rihoux, B., \& Ragin, C. C. (2013). Qualitative comparative analysis (QCA), anno 2013: reframing the comparative method's seminal statements. Swiss Political Science Review, 19(2), 233-245.

Rohlfing, I. (2012). Analyzing multilevel data with QCA: a straightforward procedure. International Journal of Social Research Methodology, 15(6), 497-506.

Sayer, A. (2000). Realism and social science. London: Sage.

Schepis, D., Purchase, S., \& Ellis, N. (2014). Network position and identity: A language-based perspective on strategizing. Industrial Marketing Management, 43(4), 582-591.

Schiele, H., Calvi, R., \& Gibbert, M. (2012). Customer attractiveness, supplier satisfaction and preferred customer status: Introduction, definitions and an overarching framework. Industrial Marketing Management, 41(8), 1178-1185.

Schneider, C. Q., \& Grofman, B. (2006). It might look like a regression equation... but it's not! An intuitive approach to the presentation of QCA and fs/QCA results. Conference on "Comparative Politics: Empirical Applications of Methodological Innovations", Sophia University, Tokyo, Japan, 15-17.

Schneider, P., \& Sadowski, D. (2010). Governance configurations and academic outcomes: The example of Ph. D. education, No. 01/2010, IAAEG Discussion Paper Series.

Schneider, C. Q. \& Wagemann, C. (2010). Qualitative comparative analysis (QCA) and fuzzysets: Agenda for a research approach and a data analysis technique. Comparative Sociology, 9(3), 376-396.

Schneider, C. Q., \& Wagemann, C. (2012). Set-theoretic methods for the social sciences: A guide to qualitative comparative analysis. Cambridge: Cambridge University Press.

Slater, S. F., \& Narver, J. C. (1995). Market orientation and the learning organization. Journal of Marketing, 59(3), 63-74.

Thibaut, N., \& Kelley, H. (1959). The social psychology of groups. New York, Wiley.

Tóth, Z., Thiesbrummel, C., Henneberg, S. C., \& Naudé, P. (2015). Understanding configurations of relational attractiveness of the customer firm using fuzzy set QCA. Journal of Business Research, 68(3), 723-734.

Turnbull, P., Ford, D., \& Cunningham, M. (1996). Interaction, relationships and networks in business markets: an evolving perspective. Journal of Business \& Industrial Marketing, 11(3/4), 44-62.

Van der Heijden, J. (2014). The Role of Government in Voluntary Environmental Programs: A Fuzzy Set Qualitative Comparative Analysis (fsQCA). Forthcoming in Public Administration.

Verweij, S., Klijn, E. H., Edelenbos, J., \& Van Buuren, A. (2013). What makes governance networks work? A fuzzy set qualitative comparative analysis of 14 Dutch spatial planning projects. Public Administration, 91(4), 1035-1055.

Wang, W. (2015). Exploring the Determinants of Network Effectiveness: The Case of Neighborhood Governance Networks in Beijing. Forthcoming in Journal of Public Administration Research and Theory 
Woodside, A. G. (2013). Moving beyond multiple regression analysis to algorithms: Calling for adoption of a paradigm shift from symmetric to asymmetric thinking in data analysis and crafting theory, Journal of Business Research, 66(4), 463-472.

Young-Ybarra, C., \& Wiersema, M. (1999). Strategic flexibility in information technology alliances: The influence of transaction costs economics and social exchange theory. Organization Science, 10(4), 439-459.

Zaheer, A., McEvily, B., \& Perrone, V. (1998). Does trust matter? Exploring the effects of interorganizational and interpersonal trust and performance. Organization Science, 9(2), 141-159. 
Figure 1 Conceptual Model of the RAC Conditions

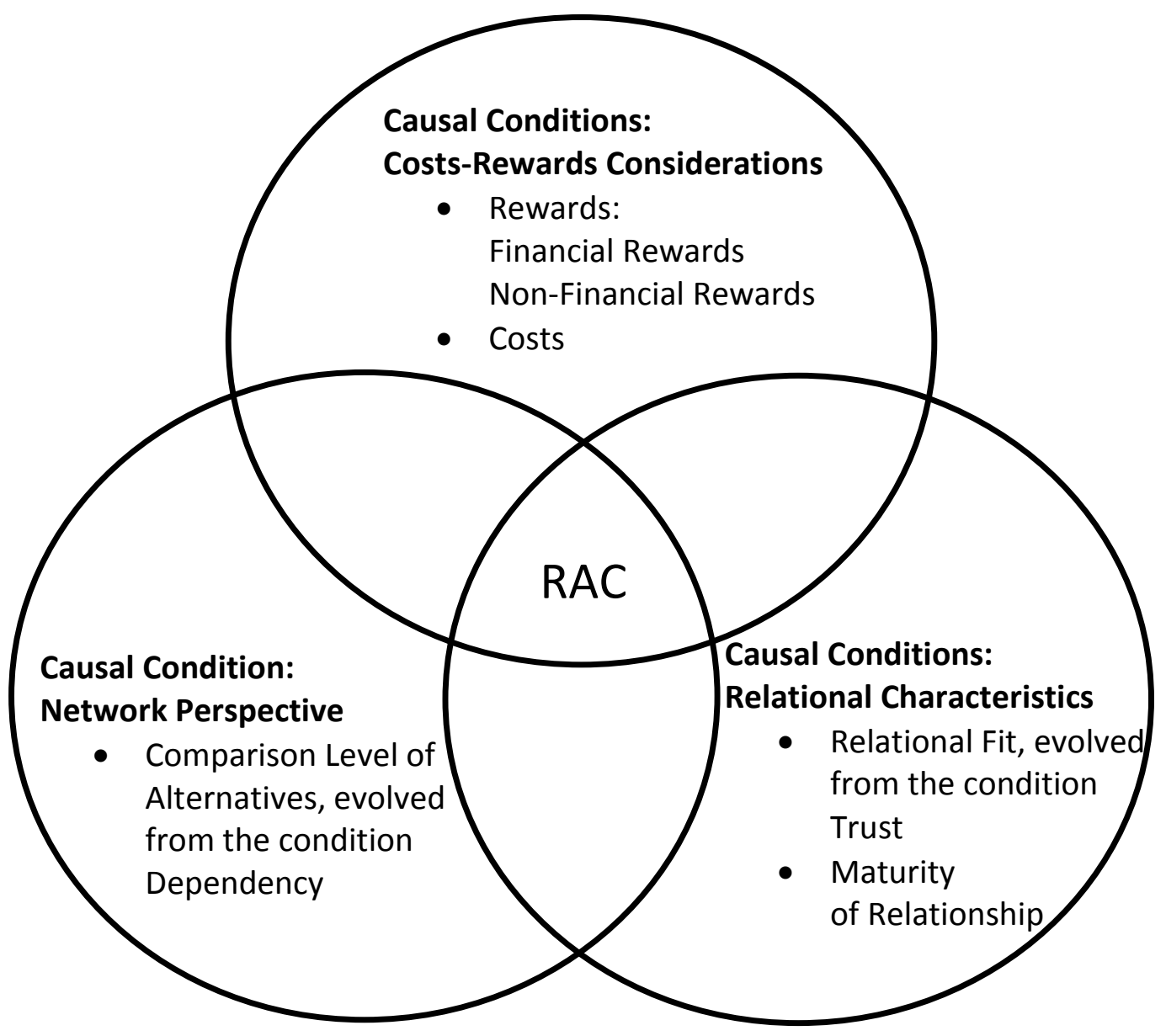

Note: Categorization of conditions is inspired by Leischnig \& Krasper-Brauer (2014) 


\section{Table 1 Position and industry background of interviewees/suppliers and the chosen customer firm}

\begin{tabular}{|c|c|c|c|c|c|}
\hline $\begin{array}{l}\text { \#Cas } \\
\text { e }\end{array}$ & $\begin{array}{l}\text { Position of Manager } \\
\text { (Supplier Side) }\end{array}$ & Industry of Supplier & $\begin{array}{l}\text { Size of } \\
\text { Supplier }\end{array}$ & $\begin{array}{l}\text { Industry of } \\
\text { Customer }\end{array}$ & $\begin{array}{l}\text { Size of } \\
\text { Customer }\end{array}$ \\
\hline 1 & Managing Director & $\begin{array}{l}\text { human resource } \\
\text { management }\end{array}$ & small & social enterprise & large \\
\hline 2 & Senior Dealer Marketing Manager & automotive & large & automotive dealer & medium \\
\hline 3 & Head of Strategic Marketing & $\begin{array}{l}\text { manufacturing } \\
\text { (equipment for energy } \\
\text { sector) }\end{array}$ & large & tool hire & large \\
\hline 4 & Director of Sales & hospitality & large & financial services & large \\
\hline 5 & Managing Director & storage management & medium & $\begin{array}{l}\text { corporate } \\
\text { relocations }\end{array}$ & medium \\
\hline 6 & $\begin{array}{l}\text { Managing Director / Customer } \\
\text { Experience \& Complaints Executive }\end{array}$ & financial services & large & football & large \\
\hline 7 & Managing Director & accountancy systems & medium & $\mathrm{NGO}$ & large \\
\hline 8 & Managing Director & confectionery & small & food retail & large \\
\hline 9 & Vice President of Technology & $\begin{array}{l}\text { cloud \& technology } \\
\text { services }\end{array}$ & medium & charity & large \\
\hline 10 & $\begin{array}{l}\text { Product Lifecycle Executive } \\
\text { Manager }\end{array}$ & engineering \& electronics & large & wind farm & large \\
\hline 11 & Program Director & education & large & governmental & large \\
\hline 12 & Managing Director & architecture design & small & construction & medium \\
\hline 13 & Customer Director & consumer goods & large & food retail & large \\
\hline 14 & Domestic Retail Director & water $\&$ waste water & large & consumer goods & large \\
\hline 15 & $\begin{array}{l}\text { Indirect Channel Executive Sales } \\
\text { Manager }\end{array}$ & petrochemicals & large & $\begin{array}{l}\text { oil products } \\
\text { distributor }\end{array}$ & large \\
\hline 16 & UK \& Ireland Sales Director & $\begin{array}{l}\text { heavy equipment } \\
\text { (for construction) }\end{array}$ & large & construction & medium \\
\hline 17 & Sales Director & recycling & large & financial services & large \\
\hline 18 & Market Intelligence Director & $\begin{array}{l}\text { information technology } \\
\text { equipment \& services }\end{array}$ & large & governmental & medium \\
\hline 19 & Managing Director & coatings \& plastics & large & $\begin{array}{l}\text { automotive } \\
\text { pigment supplier }\end{array}$ & large \\
\hline 20 & $\begin{array}{l}\text { Customer and Partner Experience } \\
\text { Director }\end{array}$ & $\begin{array}{l}\text { software \& online } \\
\text { services }\end{array}$ & large & $\begin{array}{l}\text { multichannel } \\
\text { retail }\end{array}$ & large \\
\hline 21 & Managing Director & courier delivery services & large & office stationary & large \\
\hline 22 & $\begin{array}{l}\text { Commercial Support and Planning } \\
\text { Director }\end{array}$ & baking & large & food retail & large \\
\hline 23 & UK Business Director & telecommunication & large & home retail & large \\
\hline 24 & $\begin{array}{l}\text { Senior Team Leader and } \\
\text { Communication Executive }\end{array}$ & advertising & medium & transportation & large \\
\hline 25 & Managing Director & consultancy & small & $\mathrm{NGO}$ & medium \\
\hline 26 & Managing Director & event management & small & media & small \\
\hline 27 & Sales Director & logistics & medium & retirement homes & medium \\
\hline 28 & Managing Director & electronic equipment & large & $\begin{array}{l}\text { multichannel } \\
\text { retail }\end{array}$ & large \\
\hline
\end{tabular}

Note: Size of Supplier/Customer is classified by the number of employees, according to UK governmental guidelines (www.gov.uk): small company is defined as a business below 50 employees, medium between 50 and 250 employees and large 250 employees and above 
Table 2 FsQCA articles using qualitative data

\begin{tabular}{|c|c|c|c|c|c|}
\hline Article & Context & How theory is applied? & Coding process & $\begin{array}{l}\text { Decision about set-membership } \\
\text { categories }\end{array}$ & Calibration \\
\hline $\begin{array}{l}1 \text { Basurto } \\
\text { (2013) }\end{array}$ & $\begin{array}{l}\text { Biodiversity conservation } \\
\text { in Costa Rica. }\end{array}$ & $\begin{array}{l}\text { Theoretical background is used to } \\
\text { highlight interaction between the } \\
\text { conditions in the context of the } \\
\text { research. }\end{array}$ & n.a. & $\begin{array}{l}\text { 6-value sets are applied, the } \\
\text { decision is not explained. }\end{array}$ & $\begin{array}{l}\text { Mainly based on quantitative anchors. It is } \\
\text { noted that "special care was given to } \\
\text { ensure that similar values on the Likert } \\
\text { scale from different respondents could be } \\
\text { compared" (p. 578), which increases } \\
\text { ambiguity. }\end{array}$ \\
\hline $\begin{array}{l}2 \text { Basurto \& } \\
\text { Speer }(2012)\end{array}$ & $\begin{array}{l}\text { The responsiveness of } \\
\text { Guatemalan local } \\
\text { governments. }\end{array}$ & $\begin{array}{l}\text { Theory is used for hypothesis } \\
\text { articulation, the identification of } \\
\text { conditions as well as some } \\
\text { dimensions of these conditions. }\end{array}$ & $\begin{array}{l}\text { Iterative coding. It is unclear } \\
\text { whether template had been } \\
\text { used for the analysis. }\end{array}$ & $\begin{array}{l}\text { 4-value sets based on substantive } \\
\text { case knowledge and the detailed } \\
\text { nature of data. }\end{array}$ & $\begin{array}{l}\text { Primarily based on quantitative anchors, } \\
\text { for example frequencies. }\end{array}$ \\
\hline $\begin{array}{l}3 \text { Crilly } \\
\text { (2011) }\end{array}$ & $\begin{array}{l}\text { Stakeholder orientation in } \\
\text { the multinational } \\
\text { enterprise. }\end{array}$ & $\begin{array}{l}\text { The emphasis is on linking } \\
\text { different levels of analysis, i.e. } \\
\text { resource pressures, institutional } \\
\text { pressures and organizational } \\
\text { attributes. }\end{array}$ & $\begin{array}{l}\text { 'Features' and 'drivers' are } \\
\text { identified as dimensions and } \\
\text { antecedents of local and } \\
\text { global legitimacy pressures } \\
\text { conditions. Coding is not } \\
\text { elaborated but appears to } \\
\text { embrace diversity of the } \\
\text { conditions. }\end{array}$ & $\begin{array}{l}\text { Considers 4-value and 6-value } \\
\text { sets, with the final choice of the } \\
\text { 4-value sets. Describes } \\
\text { membership sets as scales. }\end{array}$ & $\begin{array}{l}\text { Based on substantive case knowledge and } \\
\text { illustrative examples. Membership } \\
\text { categories are typologies of situations, in } \\
\text { which current status and future intentions } \\
\text { are embedded (e.g. stakeholder orientation } \\
\text { condition). }\end{array}$ \\
\hline $\begin{array}{l}4 \text { Schneider \& } \\
\text { Sadowski } \\
(2010)\end{array}$ & $\begin{array}{l}\text { Governance } \\
\text { configurations and } \\
\text { academic outcomes of } \\
\text { PhD education. }\end{array}$ & $\begin{array}{l}\text { Literature is applied to the } \\
\text { identification of conditions but } \\
\text { less for the content-description of } \\
\text { these conditions (i.e. not as } \\
\text { guidance for coding). }\end{array}$ & n.a. & $\begin{array}{l}\text { Combination of 4- and 6-value } \\
\text { fuzzy sets. Reasons of this choice } \\
\text { are not explained. }\end{array}$ & $\begin{array}{l}\text { Based on quantitative anchors where } \\
\text { applicable. Qualitative aspects are not } \\
\text { explained. }\end{array}$ \\
\hline $\begin{array}{l}5 \text { Van der } \\
\text { Heijden } \\
(2014)\end{array}$ & $\begin{array}{l}\text { Voluntary environmental } \\
\text { programs and their } \\
\text { governance. }\end{array}$ & $\begin{array}{l}\text { Identification of activities, } \\
\text { here conditions. }\end{array}$ & $\begin{array}{l}\text { Systematic coding scheme is } \\
\text { applied. }\end{array}$ & $\begin{array}{l}\text { 4-value fuzzy sets, decision not } \\
\text { explained. }\end{array}$ & $\begin{array}{l}\text { Based on degrees of presence and absence, } \\
\text { i.e. } 1 \text { fully presence, } 0.67 \text { partially } \\
\text { presence, } 0.33 \text { partially absence, } 0 \text { fully } \\
\text { absent. }\end{array}$ \\
\hline $\begin{array}{l}6 \text { Verweij et } \\
\text { al. (2013) }\end{array}$ & $\begin{array}{l}\text { Governance networks of } \\
\text { Dutch spatial planning } \\
\text { projects. }\end{array}$ & $\begin{array}{l}\text { Theory is applied to identify } \\
\text { conditions. }\end{array}$ & $\begin{array}{l}\text { Not really coding but } \\
\text { categorisation of cases along } \\
\text { identified key characteristics. }\end{array}$ & $\begin{array}{l}\text { 4-value fuzzy sets, decision not } \\
\text { explained. }\end{array}$ & $\begin{array}{l}\text { Quantitative anchors (e.g. number of } \\
\text { conflicts) but also qualitative aspects, such } \\
\text { as the intensity of these conflicts. }\end{array}$ \\
\hline $\begin{array}{l}7 \text { Wang } \\
(2015)\end{array}$ & $\begin{array}{l}\text { Neighbour governance } \\
\text { networks in Beijing. }\end{array}$ & $\begin{array}{l}\text { Theory is used for the } \\
\text { identification of the conditions } \\
\text { and justification of a } \\
\text { configurational approach. }\end{array}$ & $\begin{array}{l}\text { No coding, interviews provide } \\
\text { overall impressions that are } \\
\text { analysed along with other } \\
\text { types of data. }\end{array}$ & $\begin{array}{l}\text { Continuous fuzzy sets but the } \\
\text { process is not explained. }\end{array}$ & $\begin{array}{l}\text { Based on a combination of qualitative, } \\
\text { quantitative and social network analysis } \\
\text { data. Only network measures are } \\
\text { explained. }\end{array}$ \\
\hline
\end{tabular}


Table 3 Conditions, their operational definitions and theoretical background

\begin{tabular}{|c|c|c|c|}
\hline \multicolumn{2}{|c|}{ Conditions of RAC } & Operational Definition of Condition & Source \\
\hline \multirow[t]{2}{*}{ Rewards } & Financial & $\begin{array}{l}\text { Current and expected financial benefits of } \\
\text { the relationship with the Customer }\end{array}$ & \multirow{2}{*}{$\begin{array}{l}\text { Blau, 1964; Thibaut and Kelley, } \\
\text { 1959; Lambe et al., 2001; } \\
\text { Emerson, } 1976\end{array}$} \\
\hline & $\begin{array}{l}\text { Non- } \\
\text { Financial }\end{array}$ & $\begin{array}{l}\text { Current and expected non-financial } \\
\text { benefits of the relationship with the } \\
\text { Customer, such as reputational benefits, } \\
\text { and benefits related to branding, } \\
\text { knowledge sharing, networking, } \\
\text { recommendations/referrals }\end{array}$ & \\
\hline \multicolumn{2}{|l|}{ Costs } & $\begin{array}{l}\text { Current and expected costs of managing } \\
\text { the relationship as well as operational } \\
\text { costs. }\end{array}$ & $\begin{array}{l}\text { Blau, 1964; Thibaut and Kelley, } \\
\text { 1959; Das \& Teng, 2002; Molm, } \\
1991\end{array}$ \\
\hline \multicolumn{2}{|c|}{$\begin{array}{l}\text { Comparison Level of } \\
\text { Alternatives (CLA) }\end{array}$} & $\begin{array}{l}\text { The Comparison Level of Alternatives } \\
\text { reflects on the perception and knowledge } \\
\text { of the availability of potential alternatives } \\
\text { that broadens the relationship-specific } \\
\text { dependency aspect with a contextual } \\
\text { network perspective. }\end{array}$ & $\begin{array}{l}\text { Partly literature (Blau, 1964; } \\
\text { Cook and Rice, 2003; Thibaut and } \\
\text { Kelley, 1959; Emerson, 1962; } \\
\text { Lambe et al., 2001) and partly } \\
\text { based on emerged coding. }\end{array}$ \\
\hline \multicolumn{2}{|c|}{ Relational Fit } & $\begin{array}{l}\text { The perceived fit at a relational level } \\
\text { between Customer and Supplier, including } \\
\text { different relational aspects such as trust, } \\
\text { communication frequency and intensity, } \\
\text { geographical proximity, similarities and } \\
\text { differences between organizational } \\
\text { cultures and relational fit at the level of } \\
\text { inter-personal relationships. }\end{array}$ & $\begin{array}{l}\text { Starting point was trust (Copranzo } \\
\text { et al., 2005; Molm et al., 2000) } \\
\text { informed by emerging coding. } \\
\text { Some aspects of Relational Fit } \\
\text { were identified based on previous } \\
\text { literature and then in data (e.g. } \\
\text { shared values and strategies, } \\
\text { Mortensen et al., 2008), some } \\
\text { derived from data (e.g. } \\
\text { geographical proximity, } \\
\text { transparency) }\end{array}$ \\
\hline \multicolumn{2}{|c|}{ Relationship Maturity } & $\begin{array}{l}\text { The relationship maturity describes the } \\
\text { perceived maturity of the relationship from } \\
\text { the Supplier`s perspective. The } \\
\text { relationship maturity condition is not based } \\
\text { on a linear measure that means that the } \\
\text { actual length of the relation does not } \\
\text { directly indicate the relationship maturity } \\
\text { and the different maturity categories do not } \\
\text { necessary follow a step-by-step linear } \\
\text { sequence. For example, a once declining } \\
\text { relationship may change into a build-up } \\
\text { phase or a new relationship can reach the } \\
\text { declining phase without reaching maturity. }\end{array}$ & $\begin{array}{l}\text { Ellegaard and Ritter (2006) } \\
\text { suggest that attractiveness may } \\
\text { differ in different stages of } \\
\text { business relationships. For the } \\
\text { maturity categories Jap and } \\
\text { Ganesan (2000) is applied. }\end{array}$ \\
\hline
\end{tabular}


Table 4 Membership Evaluation Template (MET) for the Relational Fit Condition

\begin{tabular}{|c|c|c|c|c|}
\hline \multicolumn{5}{|c|}{$\begin{array}{l}\text { Membership Evaluation Template (MET) Case number: } \\
\text { Membership in the set of 'Customer Relationships with good Relational Fit' }\end{array}$} \\
\hline $\begin{array}{l}\text { Overall Case } \\
\text { Description from a } \\
\text { Relational Fit } \\
\text { Perspective }\end{array}$ & \multicolumn{4}{|c|}{$\begin{array}{l}\text { A sustainable but very difficult relationship with various problems at an inter- } \\
\text { personal level (e.g. hidden agendas) as well as differences in corporate } \\
\text { communication style (e.g. negotiations). The Customer`s professional qualities } \\
\text { are highly valued but power games around branding issues and ownership create a } \\
\text { distrustful atmosphere with regular conflicts. }\end{array}$} \\
\hline $\begin{array}{l}\text { Dimensions } \\
\# 1\end{array}$ & $\begin{array}{l}\text { Context-specific } \\
\text { Description } \\
\# 2\end{array}$ & $\begin{array}{l}\text { Intensity } \\
\text { /Relative } \\
\text { Importance } \\
\# 3\end{array}$ & $\begin{array}{l}\text { Direction } \\
\text { /Effect on } \\
\text { Membership } \\
\# 4\end{array}$ & $\begin{array}{l}\text { Illustrative Quote(s) } \\
\# 5\end{array}$ \\
\hline $\begin{array}{l}\text { Customer's } \\
\text { opportunistic } \\
\text { behavior }\end{array}$ & $\begin{array}{l}\text { Branding issues } \\
\text { and problems } \\
\text { with information } \\
\text { sharing }\end{array}$ & $\begin{array}{l}\text { Medium } \\
\text { /High }\end{array}$ & Negative & $\begin{array}{l}\text { "...they are more interested in } \\
\text { their brand than in our brand" }\end{array}$ \\
\hline $\begin{array}{l}\text { Trust issues } \\
\text { (inter- } \\
\text { organizational } \\
\text { level) }\end{array}$ & $\begin{array}{l}\text { No trust, contact } \\
\text { person is } \\
\text { described as } \\
\text { intelligent but } \\
\text { very opiniated } \\
\text { and } \\
\text { argumentative }\end{array}$ & Moderate & Negative & $\begin{array}{l}\text { "I don't trust them. (...) [Our } \\
\text { company] doesn`t trust them." }\end{array}$ \\
\hline Professional trust & $\begin{array}{l}\text { There is trust in } \\
\text { the abilities and } \\
\text { skills of the } \\
\text { customer }\end{array}$ & Medium & Positive & $\begin{array}{l}\text { "They are a good } \\
\text { organization, they are } \\
\text { professional, they make } \\
\text { profits..." }\end{array}$ \\
\hline Frequent conflicts & $\begin{array}{l}\text { Even minor } \\
\text { problems end up } \\
\text { in conflicts }\end{array}$ & High & Negative & $\begin{array}{l}\text { "There's always going to be } \\
\text { conflict, but the conflict is } \\
\text { always exaggerated when } \\
\text { we re dealing with them. (...) } \\
\text { Any potential discrepancy, } \\
\text { argument, interaction, always } \\
\text { end up in conflict with them." }\end{array}$ \\
\hline $\begin{array}{l}\text { Difference in size } \\
\text { of organizations }\end{array}$ & $\begin{array}{l}\text { Organizational } \\
\text { inertia deriving } \\
\text { from size }\end{array}$ & Low & $\begin{array}{l}\text { Negative / } \\
\text { Neutral }\end{array}$ & $\begin{array}{l}\text { "Because they are relatively } \\
\text { small, they can move a lot } \\
\text { quicker than we move." }\end{array}$ \\
\hline $\begin{array}{l}\text { Differences in } \\
\text { organizational } \\
\text { cultures }\end{array}$ & $\begin{array}{l}\text { Different } \\
\text { negotiation } \\
\text { styles } \\
\text { (difficulties) and } \\
\text { lack of the sense } \\
\text { of collaboration }\end{array}$ & Moderate & Negative & $\begin{array}{l}\text { "[Customer] is supporting the } \\
\text { contact person`s } \\
\text { argumentative behavior." }\end{array}$ \\
\hline
\end{tabular}




\begin{tabular}{|c|c|c|c|c|}
\hline $\begin{array}{l}\text { Changes in } \\
\text { ownership }\end{array}$ & $\begin{array}{l}\text { The holding } \\
\text { company behind } \\
\text { the Customer } \\
\text { became part of a } \\
\text { company where } \\
\text { Supplier bought } \\
\text { a } 40 \% \text { stake }\end{array}$ & $\begin{array}{l}\text { High } \\
\text { /Medium }\end{array}$ & Negative & $\begin{array}{l}\text { "...when the tail tries to wag } \\
\text { the dog... they are trying to } \\
\text { wag us. They are telling us } \\
\text { what we should be doing, and } \\
\text { what products we should } \\
\text { have, that type of thing."” }\end{array}$ \\
\hline $\begin{array}{l}\text { Supporting } \\
\text { quantitative data }\end{array}$ & \multicolumn{4}{|l|}{ none } \\
\hline $\begin{array}{l}\text { Set Membership in } \\
\text { 6-Value Fuzzy Set }\end{array}$ & \multicolumn{4}{|c|}{0.2 ('mostly but not fully out') } \\
\hline
\end{tabular}

Note: The examples are presented for demonstration purposes and are not exhaustive. This example shows a "relatively low" membership in the 'Customer Relationships with Good Relational Fit'

\section{Qualitative anchors: Meanings attached to fuzzy values}

1 Overall intense (and/or various) positive dimensions

0.8 Intense (and/or various) positive dimensions with very few negative dimensions

0.6 Mostly positive dimensions with some (/important) negative dimensions

0.4 Mostly negative dimensions with some (/important) positive dimensions

0.2 Intense (and/or various) negative dimensions with very few positive dimensions

0 Overall intense (and/or various) negative dimensions

Note: The examples presents the evaluation of a 6 -value fuzzy set. 
Table 5 Overview of Solutions for RAC

\begin{tabular}{|c|c|c|c|c|c|c|}
\hline & \multicolumn{6}{|c|}{ Relational Attractiveness of the Customer } \\
\hline & \multicolumn{4}{|c|}{ Presence } & \multicolumn{2}{|c|}{ Absence } \\
\hline & $1 \mathbf{a}$ & $1 \mathrm{~b}$ & $1 \mathrm{c}$ & 1d & $2 a$ & $2 \mathbf{b}$ \\
\hline Maturity & & $\otimes$ & $\bigotimes$ & $\bullet$ & & $\otimes$ \\
\hline Financial Rewards & $\bullet$ & $\otimes$ & $\bullet$ & & $\otimes$ & $\otimes$ \\
\hline Non-Financial Rewards & 0 & 0 & $\otimes$ & & $\bigotimes$ & $\otimes$ \\
\hline Costs & $\otimes$ & $\otimes$ & $\otimes$ & $\otimes$ & 0 & 0 \\
\hline CLA & $\otimes$ & $\bullet$ & & $\bullet$ & $\otimes$ & \\
\hline Relational Fit & 0 & & 0 & 0 & $\otimes$ & $\otimes$ \\
\hline Consistency & 0.89 & 0.95 & 0.95 & 0.94 & 0.93 & 0.95 \\
\hline Raw coverage & 0.52 & 0.36 & 0.36 & 0.48 & 0.43 & 0.36 \\
\hline Unique coverage & 0.10 & 0.03 & 0.02 & 0.07 & 0.16 & 0.08 \\
\hline Solution coverage & & 0.70 & & & & \\
\hline Solution consistency & & 0.87 & & & & \\
\hline
\end{tabular}

Note: black circles indicate the presence of the conditions; circles with " $\mathrm{x}$ " indicate the absence; large circles indicate core conditions; small circles indicate peripheral conditions. 
Table 6 Overview of Solutions for Very High RAC

\begin{tabular}{cc}
\cline { 2 - 2 } & Very High RAC \\
\cline { 2 - 2 } Maturity & $\bigotimes$
\end{tabular}

Financial Rewards

Non-Financial Rewards

Costs

$\otimes$

CLA

$\bigotimes$

Relational Fit

$\begin{array}{ll}\text { Consistency } & 0.93 \\ \text { Raw coverage } & 0.47 \\ \text { Unique coverage } & 0.47 \\ & \\ \text { Solution coverage } & 0.47 \\ \text { Solution consistency } & 0.93\end{array}$

Note: black circles indicate the presence of the conditions; circles with " $x$ " indicate the absence; large circles indicate core conditions; small circles indicate peripheral conditions. 